\title{
Da gestão por competências às competências gerenciais do enfermeiro
}

\author{
From managment competencies to nurse managerial competencies \\ De la gestión por competencias a las competencias gerenciales del enfermero
}

Patrícia de Oliveira Furukawa', Isabel Cristina Kowal Olm Cunha'

'Universidade Federal de São Paulo. Departamento de Enfermagem.

Grupo de Estudos e Pesquisas em Administração de Serviços de Saúde e Gerenciamento de Enfermagem. São Paulo, SP

Submissão: 03/04/2010

Aprovação: 20/06/2010

\section{RESUMO}

Este artigo trata-se de uma revisão bibliográfica Que teve como objetivos coletar maiores informações acerca da gestão por competências; entender os conceitos de perfil e competências na gestão de pessoas; compreender a Questão das competências profissionais e a sua relação com as competências da organização; e por fim identificar as competências gerenciais necessárias ao trabalho do enfermeiro sob o aspecto do mercado de trabalho. A literatura evidenciou Que o conceito de competência apresenta grandes resultados Quando aplicado na gestão de pessoas, podendo proporcionar no contexto dos serviços de saúde, benefícios tanto para as organizações Quanto para os profissionais e pacientes. Para isso, é necessário que os serviços de saúde se apropriem desse conhecimento, como possibilidade de alcançarem melhores resultados, assim como instituições de ensino e enfermeiros, Que buscam uma formação Que corresponda aos desafios da profissão e do mercado de trabalho.

Descritores: Enfermagem; Gestão em saúde; Competência profissional.

\section{ABSTRACT}

This article is a literature review that aimed to collect more information about the competencies management, understand the concepts of profile and competencies in the managing people; understand the issue of professional competence and its relationship with the organization's competencies; and finally identify the managerial competencies necessary to work of the nurse on the aspect of the labor market. The literature showed that the concept of competence shows great results when applied in the people management arena. It also can provide in the context of health services, benefits for the organizations and for the professionals and patients. For that, it's required that health services to take the ownership of this knowledge as possibility to achieve better results, as well as educational institutions and nurses that seek for information and training to achieve the challenges of the profession and the labor market.

Key words: Nursing; Health management; Professional competence.

\section{RESUMEN}

Este artículo es una revisión de la literatura Que tiene por objeto recopilar más información sobre la gestión de competencias; entender los conceptos de perfil y competencias em la gestión de personas; comprender la cuestión de las competências profesionales y su relación con las competencias de la organización; y finalmente, identificar las competencias gerenciais necesarias para trabajo de enfermera en el aspecto del mercado laboral. A literatura mostró que el concepto de competencias, muestra grandes resultados cuando se aplican en la gestión de personas y pueden proporcionar el contexto de los servicios de salud, beneficios para as organizaciones y para los profesionales y los pacientes. Esto requiere que los servicios de salud a tomar posesión de este conocimiento como sea posible para lograr mejores resultados, así como instituciones educativas y las enfermeras, la búsqueda de una formación frente a los retos de la profesión y el mercado laboral.

Descriptores: Enfermería; Gestión en salud; Competencia profesional. 


\section{INTRODUÇÃO}

As transformações decorrentes da globalização e conseQuente aumento da competitividade têm exigido mudanças por parte das organizações. A globalização(1) ${ }^{(1)}$ consiste no resultado de uma integração mundial dos setores econômicos e financeiros é real e irreversível.

Estas mudanças ocorreram nos diversos âmbitos das organizações, dentre eles, o de gestão. Modelos tradicionais traziam consigo uma rigidez organizacional, um vínculo à tradição e centralização das decisões. Modelos atuais de gestão trazem conceitos de inovação, flexibilidade, trabalho em equipe e decisões descentralizadas ${ }^{(2)}$. Estes novos modelos refletem a busca de caminhos para melhorar o desempenho organizacional, por meio de uma participação mais efetiva de todos os envolvidos nos processos administrativos e operacionais da empresa ${ }^{(3)}$.

A gestão por competências é uma alternativa aos modelos tradicionais de gestão, e vem cada dia mais sendo discutida pelas organizações, ainda Que pouco utilizada pelos serviços de saúde. Apesar disto, uma pesquisa realizada por Fisher e Albueuerque ${ }^{(4)}$, envolvendo grandes empresas do país, revela Que a maioria dessas organizações coloca a gestão por competências dentre as principais diretrizes Que orientarão os modelos de gestão de pessoas nos próximos anos.

$\mathrm{Na}$ área da enfermagem, a discussão sobre competências também ganhou destaque tanto no âmbito da atuação Quanto da formação profissional. De maneira a contribuir para esse conhecimento, este estudo teve por objetivos: coletar maiores informações acerca da gestão por competências; entender os conceitos de perfil e competências na gestão de pessoas; compreender a Questão das competências profissionais e a sua relação com as competências da organização; e por fim identificar as competências gerenciais necessárias ao trabalho do enfermeiro sob o aspecto do mercado de trabalho.

\section{MÉTODO}

Tratou-se de uma revisão bibliográfica não estruturada acerca do tema competências, nas áreas da Administração Geral e em Enfermagem realizada no ano de 2008. As referências foram levantadas a partir das bases de dados da Literatura Internacional em Ciências da Saúde (MEDLINE), da Literatura Latino-Americano e do Caribe Ciências da Saúde (LILACS) e da Scientific Electronic Library Online (SciELO) publicados entre 2002 a 2008. Os descritores utilizados foram: gerência, gestão em saúde, competência profissional, enfermagem.

Além das bases de dados, foram também utilizados artigos, livros, dissertações e teses de Bibliotecas de Universidades, como da Fundação Getulio Vargas (FGV), da Universidade de São Paulo (USP), da Universidade Federal de São Paulo (UNIFESP/EPM), dentre outras. A seleção inicial resultou em 95 referências, sendo Que destas, 30 foram incluídas neste estudo. Após uma leitura analítica desses materiais, os textos foram classificados por categorias temáticas.

\section{RESULTADOS E DISCUSSÃO}

As categorias temáticas resultantes dessa revisão da literatura
Que permitiram alcançar os objetivos propostos com este estudo foram: gestão por competências; perfil e competências na gestão de pessoas; compreendendo a Questão das competências individuais/profissionais; e competências gerenciais do enfermeiro.

\section{Gestão por competências}

A valorização do conhecimento, sobretudo, em relação aos colaboradores Que fazem parte de uma organização, provocou também mudanças na gestão de pessoas. Com a percepção de Que trabalhador tem um importante papel no sucesso organizacional, houve uma preocupação referente às competências necessárias aos profissionais.

Além do aspecto do trabalhador, as empresas também procuram desenvolver competências organizacionais Que criem vantagens competitivas. Sob o ponto de vista empresarial ${ }^{(5)}$, é o conhecimento aplicado Que gera capacidade de produzir resultados, ou seja, competência.

Nesse sentido, as competências podem então ser classificadas como individuais ou profissionais (aeuelas relacionadas a indivíduos) e organizacionais (aQuelas inerentes à organização como um todo), ressaltando-se Que as competências profissionais, aliadas a outros recursos, dão origem e sustentação às competências organizacionais ${ }^{(6)}$.

No Que se refere às competências individuais, relacionadas à prática da gestão de pessoas, algumas empresas mais avançadas têm realizado a captação, desenvolvimento e remuneração de pessoas baseado em competências estratégicas ao negócio ${ }^{(4)}$. Ao incorporar o conceito de competência, novos instrumentos e novas técnicas são empregadas, visando identificar pessoas com potencial de crescimento, flexibilidade e com pensamento estratégico. Os processos de treinamento e desenvolvimento assumem novos contornos, criando-se inclusive em algumas empresas o conceito de universidade corporativa, em Que todo o processo de desenvolvimento das pessoas deve estar alinhado à definição de estratégias de negócio e competências essenciais da organização. E por fim, em termos de remuneração, criam-se modelos próprios, estabelecendo os níveis de competência e a compensação condizente com cada nível ${ }^{(7)}$.

lá o conceito de competência organizacional tem suas raízes na abordagem da organização como um portfólio de recursos (resource based view of the firm). Essa abordagem considera Que toda a empresa tem um portfólio: físico, financeiro, intangível (marca, imagem), organizacional (sistemas administrativos, cultura organizacional) e de recursos humanos. As competências seriam formadas a partir de recursos e as estratégias elaboradas a partir de grupos de recursos, ou seja, a partir das competências ${ }^{(7)}$.

Dentre as competências organizacionais, existem algumas Que são essenciais, as core competences, Que são aQuelas Que conferem vantagem competitiva, gerando valor distinto percebido pelo cliente ${ }^{(8)}$. Dessa maneira, uma organização possui diversas competências organizacionais, localizadas em diversas áreas (denominada também de competências funcionais), porém apenas algumas são competências essenciais, Que a diferenciam e lhe garantem vantagem competitiva sustentável perante outras empresas ${ }^{(7)}$.

Portanto, a efetividade da organização resulta da capacidade de articular o seu direcionamento estratégico com as competências da empresa, dos grupos e as competências individuais ${ }^{(9)}$. Embora 
tenham origens distintas, as competências organizacionais e individuais estão relacionadas, já Que se entende ${ }^{(10)}$ Que as competências individuais formam a base das competências organizacionais.

Sob essa perspectiva, a gestão por competências trata-se de um processo contínuo Que toma como referência a estratégia corporativa para orientar esforços em torno da captação e/ou desenvolvimento de competências necessárias à consecução de objetivos organizacionais ${ }^{(6)}$. Como as estratégias organizacionais podem ser mutáveis, uma competência essencial hoje pode não ser a mesma amanhã, assim como a busca e o desenvolvimento de competências individuais podem ser alteradas, conforme as necessidades atuais de cada empresa.

Os benefícios e consequências da utilização da gestão por competência para as organizações levam a uma visualização do "todo" em função do autodesenvolvimento de cada profissional, tornando-se um diferencial, tanto para este como às instituições ${ }^{(11)}$. Nesse modelo de gestão, investir em pessoas significa investir na empresa. A organização ao transferir seu patrimônio de conhecimento para as pessoas enriquece-as e prepara-as para enfrentar novas situações profissionais e pessoais, na organização ou fora delas. As pessoas, por sua vez, ao desenvolverem sua capacidade individual, transferem para a organização seu aprendizado, capacitando-a a enfrentar novos desafios ${ }^{(12)}$.

\section{Perfil e competências na gestão de pessoas}

A fim de atender às novas demandas do mercado de trabalho, provocadas pelas mudanças na gestão de pessoas, diversas discussões são realizadas em torno do tema "perfil profissional". Isso porQue os desafios impostos às organizações para sobreviverem no mercado competitivo, na verdade, são transferidos às pessoas Que nela exercem sua função ${ }^{(13)}$. Portanto, os profissionais precisam se adequar ao perfil demandado pelo mercado de maneira a responder às exigências atuais, seja para se inserir no cargo como para manter-se no mesmo.

Por outro lado, há também a preocupação por parte das empresas, em possuir profissionais, especialmente aQueles em posição de liderança, capacitados para realizar ações estratégicas Que agreguem valor à instituição, ao invés de ser um obstáculo a mais na busca de melhores resultados. "Isso significa, Que o homem pode ser considerado como um agente facilitador ou impeditivo para o alcance dos objetivos organizacionais"(14), o Que é, especialmente, verdade Quando nos referimos a pessoas com poder decisório sobre processos e colaboradores.

Portanto, é importante adequar a pessoa ao cargo, a fim de que se possam ter resultados mensuráveis pontuados na eficácia e eficiência. Esta adeQuação começa a partir da captação dos recursos humanos, pois para realizar adeQuadamente um processo de seleção de pessoal, é necessário primeiro traçar o perfil e as competências Que a organização espera desse profissional.

Segundo Souza ${ }^{(15)}$, "perfil" são informações Que uma pessoa deve possuir para assumir uma determinada função e Que são importantes para se estabelecer um padrão mínimo de características para os colaboradores. Até recentemente, a principal exigência ao profissional, é que o mesmo tivesse uma sólida base de conhecimentos técnicos específicos, Que parecia estar garantida por sua formação em boas escolas ou faculdades. Atualmente outros fatores mostram-se igualmente importantes ${ }^{(2)}$. Isso inclui as competências Que desenvolvem simultaneamente a assimilação de conhecimentos, integração de habilidade e a escolha de atitudes relevantes para um contexto organizacional e para a obtenção de alto desempenho, em uma perspectiva de mobilização desses recursos sob condições específicas representadas pelo ambiente de trabalho ${ }^{(16)}$.

Apesar de observar-se Que perfil e competência estão interrelacionados e por vezes se confundem, entende-se que, existem determinadas informações sobre o perfil do indivíduo, Que embora não possam ser caracterizadas como competências, não deixam de ser relevantes na contratação de um profissional. Isso inclui dados pessoais, formação, experiências profissionais, traços de personalidade e outros Que, ao contrário das competências, muitas vezes não podem ser desenvolvidos no âmbito organizacional.

Para Fleury e Fleury ${ }^{(7)}$, "o conceito de competência só revela seu poder heurístico, Quando aprendido no contexto das transformações do mundo do trabalho, Quer seja nas empresas, Quer seja nas sociedades". Nesse sentido, as organizações têm um papel fundamental no desenvolvimento de competências dos profissionais. Para exigir que o indivíduo seja competente naquilo Que a empresa necessita, esta deve proporcionar condições, para Que ele atinja esse objetivo. "Trabalhar em organizações que lhe dê condições de se desenvolver nas áreas certas, ser reconhecido por mérito e não por favorecimento pessoal, cria situações Que estimulam a busca pelo desenvolvimento"(17).

A aplicação do conceito de competências na gestão de pessoas ultrapassa as abordagens tradicionais, cujo foco é o cargo a ser ocupado, para direcionar-se ao profissional e suas competências individuais. Para Ruthes e Cunha ${ }^{(18)}$, a gestão por competências vai muito além de aspectos relacionados a cargos e salários. Envolve estratégias diferenciadas de gestão de pessoas e discute, dentro de um conceito próximo à filosofia da Qualidade Total, a noção de agregação de valores à organização e sociais aos profissionais.

\section{Compreendendo a Questão das competências individuais/ profissionais}

Uma das primeiras referências para o movimento das competências na gestão de pessoas nas organizações foi feita por David McClelland ${ }^{(19)}$, em 1973, Que propôs selecionar por competência e não pelo Quoeficiente de Inteligência (QI). Em seus trabalhos fica evidente um mundo mais dinâmico na compreensão da ação humana orientada para resultados. Qualidades tais como autoconfiança integrada com habilidades analíticas e de síntese superam a dicotomia da inteligência e personalidade até então.

Nesta abordagem, a competência passa a ser compreendida como um conjunto de conhecimentos, habilidades e atitudes Que justificam um alto desempenho, na medida em Que há pressupostos de Que os melhores desempenhos estão fundamentados na inteligência e personalidade das pessoas ${ }^{(7)}$.

Nas décadas de 1980 e 1990, a definição de competência associada ao estoque de recursos Que a pessoa detém, começou a ser contestada por autores franceses e ingleses Que procuraram associar o conceito às realizações e àQuilo Que as pessoas proveem, produzem e/ou entregam ${ }^{(12)}$. Para Le Boterf ${ }^{(20)}$, um desses autores, a competência não é um estado ou um conhecimento Que se tem nem é resultado de treinamento. Competência é colocar em prática, 
o Que se sabe em um determinado contexto. Há competência apenas Quando há ação, ou seja, saber ser e saber mobilizar o repertório individual em diferentes situações.

Atualmente, o conceito de competências é entendido como o somatório dessas duas linhas, ou seja, de características da pessoa (abordagem americana) e de entrega Que levará a agregação de valor (abordagem européia) ${ }^{(12)}$.

$\mathrm{Na}$ primeira, os três grandes eixos da competência são: conhecimentos (saber); habilidades (saber-fazer); atitudes (saber ser/agir). O conhecimento corresponde a uma série de informações assimiladas e estruturadas pelo indivíduo; a habilidade corresponde à capacidade de aplicar e fazer uso do conhecimento adouirido; e a atitude refere-se aos aspectos sociais e afetivos relacionados ao trabalho que explicam o comportamento do indivíduo ${ }^{(21)}$.

Na segunda, a competência é um saber agir responsável, reconhecido pelos outros. Implica em saber como mobilizar, integrar e transferir os conhecimentos, recursos e habilidades num contexto profissional determinado ${ }^{(20)}$.

Baseados nessa compreensão, os autores brasileiros Fleury e Fleury $^{(7)}$ definem competência como "um saber agir responsável e reconhecido, Que implica mobilizar, integrar, transferir conhecimentos, recursos, habilidades, Que agreguem valor econômico à organização e valor social ao indivíduo". Este conceito é complementado por Dutra ${ }^{(12)}$, como a capacidade de entrega da pessoa. Assim, a competência entregue é caracterizada, como agregação de valor ao patrimônio de conhecimentos da organização.

Ao considerar que a competência se consolida a partir da mobilização de recursos para a obtenção de um resultado, subtendese Que ela possa ser construída, aperfeiçoada e corrigida ${ }^{(9)}$. Assim, o seu desenvolvimento trata-se de um processo contínuo Que envolve busca e aprendizado por parte dos profissionais.

Com isso, há a necessidade de pessoas dispostas a aprender e Que saibam aprender. O desempenho eficaz (o ser competente) é determinado pela maneira com as pessoas absorvem, processam e reconfiguram saberes, conferindo novos significados aos aprendizados, para mobilizá-los criticamente diante de novas situações ${ }^{(16)}$.

Os saberes Que compõem esse aprendizado e Que leva a competência diferem-se, conforme as necessidades da empresa e da posição ocupada pelo indivíduo. Uma vez Que as organizações necessitam de profissionais com diferentes competências, as competências individuais exigidas não são as mesmas para todas as pessoas. As competências requeridas para uma pessoa Que ocupa posição gerencial é diferente de uma pessoa Que ocupa posição técnica por exemplo ${ }^{(12)}$.

A definição e o desenvolvimento dessas competências individuais são um desafio, inclusive para a área da saúde. No Que se refere especificamente ao papel do enfermeiro como gestor do cuidado prestado ao paciente, muitas são as competências gerenciais necessárias a este profissional Que requerem atenção, visto Que refletem na assistência de saúde prestada às pessoas e no sucesso das instituições.

\section{Competências gerenciais do enfermeiro}

As competências gerenciais compreendem uma dimensão das competências individuais, sendo consideradas, como o "conjunto de capacidades construído e desenvolvido pelo gerente e Que articulados e mobilizados em função das diferentes situações, necessidades ou desafios, possibilitam o alcance das estratégias empresariais"(10).

Em razão disto, as competências gerenciais correspondem a uma importante ferramenta para a instituição, já Que de acordo com Ruas (22) "são aquelas Que se pretende Que "coloquem as propostas e projetos organizacionais e funcionais (áreas) em ação'”.

Para atingir esses objetivos, as pessoas Que possuem cargos gerenciais, além da necessidade de desenvolver suas próprias competências, devem também ser capazes de estimular o desenvolvimento de competências por parte dos membros de sua equipe de trabalho, de forma alinhada com as competências organizacionais. Para D'Amélio ${ }^{(10)}$, as competências gerenciais possibilitam o afloramento de competências nos demais níveis (individuais, funcionais e essenciais), na medida em Que mobilizam pessoas para o alcance de resultados, estimulando seu crescimento profissional, otimizando recursos e atendendo às necessidades e expectativas dos clientes. Nesse contexto, o gerente tem uma forte influência no desenvolvimento de pessoas e no desempenho organizacional, reQuerendo competências compatíveis com essas responsabilidades.

Considerando que um dos processos de trabalho em enfermagem é o Gerenciar e que os enfermeiros historicamente têm assumido cargos gerenciais de serviços de saúde, torna-se relevante para profissionais e instituições, inclusive, de ensino definir e desenvolver as competências gerenciais do enfermeiro. Para Gaidzinski et $\mathrm{a}^{(23)}$, "não há mais como negar a importância da função gerencial como elemento integrante do trabalho da enfermeira."

Embora o termo competência tenha sido inicialmente incorporado pelo mundo do trabalho, ele também passou a ser utilizado nas propostas de formação e atualização profissionais ${ }^{(24)}$. No plano do trabalho, substituiu o conceito de Qualificação e no plano da educação, deslocou o eixo de ensino centrado em saberes disciplinares para um ensino pautado em competências verificáveis em situações concretas ${ }^{(25)}$.

Quanto à formação dos enfermeiros, as Diretrizes Curriculares Nacionais (DCN) do Curso de Graduação em Enfermagem no Brasil, colocam a necessidade de dotar o profissional com relação às seguintes competências gerais: atenção à saúde, tomada de decisão, comunicação, liderança, administração e gerenciamento, e educação permanente ${ }^{(26)}$. Entre as seis competências apontadas pelas DCN, cinco podem ser caracterizadas como competências gerenciais. A atenção à saúde, apesar de poder ser entendida como finalidade indireta do trabalho gerencial, não se constitui diretamente como objeto de trabalho desenvolvido pela gerência ${ }^{(27)}$.

Especificamente com relação à atuação dos Responsáveis Técnicos dos serviços de saúde, o Conselho Regional de Enfermagem do Estado de São Paulo (COREN-SP), realizou uma pesquisa com estes profissionais, com o objetivo de identificar as competências necessárias às suas funções. Após o agrupamento das respostas, a proposta foi submetida a Consulta Pública, confirmando a necessidade das seguintes competências: liderança, comunicação, tomada de decisão, negociação, trabalho em equipe, relacionamento interpessoal, flexibilidade, empreendedorismo, criatividade, visão sistêmica e planejamento e organização(28).

Balsanelli et $\mathrm{al}^{(29)}$, também, citam como competências gerenciais necessárias para o enfermeiro: o ensino-aprendizagem, a gestão de recursos, comunicação, trabalho em equipe, gestão integrada 
de processos, tomada de decisão, flexibilidade, criatividade, foco no cliente, aquisição do conhecimento, compromisso, empreendedorismo, liderança, negociação e visão estratégica.

Nos EUA, uma pesQuisa com enfermeiros gerentes realizada pela Nursing Leadership Institute ${ }^{(30)}$ conduziu essa instituição a desenvolver um modelo de competência Que fornece orientações para o planejamento acadêmico e de formação contínua para enfermeiros gerentes. Seis categorias de competências surgiram baseadas nos resultados da investigação. Estas incluíram: domínio pessoal, eficácia interpessoal, gestão financeira, gestão de recursos humanos, cuidados (com pessoal, paciente e consigo) e pensamento sistematizado. Outras constatações importantes dessa pesquisa incluíram a falta de planejamento de carreira para se tornar um enfermeiro gerente e a necessidade de orientação formal no início da transição para a função, demonstrando Que a maioria dos enfermeiros gerentes não estava preparada, Quando assumiu o cargo, tendo tomado conhecimento sobre o trabalho sobretudo por meio de tentativa e erro.

Apesar das competências do enfermeiro serem, por vezes, discutidas separadamente entre os planos da educação e do trabalho, estas estão relacionadas, pois as competências necessárias à formação do enfermeiro são reflexos das necessidades do mercado e da população Que reQuerem profissionais competentes e conscientes de seu papel social. Peres ${ }^{(27)}$ afirma Que as mudanças ocorridas no mundo do trabalho, advindas das transformações tecnológicas e do impacto Que os interesses capitalistas exercem sobre as relações sociais, refletem na formação do enfermeiro e na Enfermagem enQuanto prática social e profissional.

Neste contexto, o enfermeiro deve se adaptar a essas exigências de maneira crítica e reflexiva, em especial, com relação às competências necessárias para seu bom desempenho profissional, a fim de sempre buscar a valorização pelo mundo do trabalho e pela sociedade.

No entanto, cabe destacar Que muitas das descrições das competências citadas como necessárias ao enfermeiro, estão mais relacionadas ao conceito de conhecimentos, habilidades e atitudes do Que ao conceito de entrega. Para Dutra ${ }^{(12)}$, embora o primeiro enfoeue possa ser aplicado sob o ponto de vista do desenvolvimento, ele é pouco instrumental nas empresas, visto Que o fato das pessoas possuírem determinado conjunto de conhecimentos, habilidades e atitudes não garantam Que elas irão agregar valor à organização, embora possam dar sustentação. Assim, para Que os processos de gestão de pessoas sejam articulados por competências em todas as suas dimensões (movimentação, desenvolvimento e valorização) é necessário um conceito mais objetivo Que seja mensurável. Ao considerar as pessoas por sua capacidade de entrega, dá-nos uma perspectiva mais adequada para avaliá-las, para orientar seu desenvolvimento e estabelecer recompensas de maneira atrelada às estratégias da organização.

Com isto, entende-se Que o conceito de competências como entrega permite Que não apenas o trabalhador e as instituições de ensino sejam responsáveis pelo desenvolvimento do indivíduo no mercado de trabalho, mas, Que as organizações, também, passem a compartilhar essa responsabilidade, ao mapear as competências individuais Que consideram necessárias para alcance de seus objetivos, desenvolvendo-as em seus colaboradores, movimentando e remunerando pelo Que eles agregam de valor à organização.

\section{CONSIDERAÇÕES FINAIS}

Através deste estudo, foi possível observar que o conceito de competências apesar de ainda ser muito discutido, apresenta grandes resultados Quando aplicado na gestão de pessoas.

Essa relação estabelecida através de um desenvolvimento mútuo, em Que as pessoas são valorizadas pela organização na medida em Que contribuem efetivamente para o seu desenvolvimento, assim como, as organizações são valorizadas pelas pessoas na medida em Que lhes oferece condições concretas para o seu desenvolvimento $^{(29)}$, vai ao encontro das expectativas das pessoas cada vez mais preocupadas em obter sua inserção no mercado de trabalho Quanto para obter maior satisfação e realização pessoal ${ }^{(12)}$.

Entende-se com isso que, o conceito de competências na gestão de pessoas proporciona benefícios tanto para as organizações Quanto aos profissionais. No contexto dos serviços de saúde, essas contribuições podem se estender também aos pacientes, à medida Que os objetivos das instituições estejam relacionados com a melhoria da Qualidade dos seus serviços.

Para tanto, é necessário Que os serviços de saúde se apropriem desse conhecimento, como possibilidade de alcançar melhor resultados, assim como instituições de ensino e enfermeiros Que buscam uma formação Que correspondam aos desafios da profissão e do mercado de trabalho.

\section{REFERÊNCIAS}

1. Hirschfeld M), Oguisso T. Visão Panorâmica da Saúde no Mundo e a Inserção do Home Care. Rev Bras Enferm 2002; 55(4): 452-9

2. Bork AMT, coordenadora. Enfermagem de excelência: da visão à ação. Rio de Janeiro: Guanabara Koogan; 2003.

3. Ferreira AA, Reis ACF, Pereira MI. Gestão Empresarial: de Taylor aos nossos dias: evolução e tendências da moderna administração de empresas. São Paulo: Pioneira, 2006.

4. Fischer AL, Albueuereue LG. Tendências de mudanças na gestão de pessoas das empresas brasileiras: DELPHI RH-20I0. São Paulo: Universidade de São Paulo; 2004.

5. Santos AR, Pacheco FF, Pereira HI, Bastos Júnior PA. Gestão do Conhecimento como Modelo Empresarial. In: Santos AR, organizador. Gestão do conhecimento: uma experiência para o sucesso empresarial. Curitiba: Champagnat; 200 I. p. I I-48.

6. Bruno-Faria MF, Brandão HP. Competências Relevantes a Profissionais da Área de T\&D de uma Organização Pública do Distrito Federal. Rev Adm Contemp 2003; 7(3): 35-56.

7. Fleury A, Fleury MTL. Estratégias empresariais e formação de competências: um Quebra cabeça caleidoscópico da indústria brasileira. São Paulo: Atlas; 2004.

8. Prahalad CK, Hamel G. The Core Competence of the Corporation. Harvard Bus Rev 1990; 68(3): 79-91.

9. Moura MCCM, Bitencourt CC. A articulação entre estratégia e 
o desenvolvimento de competências gerenciais. Rev Adm Empresas Eletron 2006; 5(I).

10. D'Amélio M. Aprendizagem de Competências gerenciais: um estudo com gestores de diferentes formações [dissertação]. São Paulo: Universidade Presbiteriana Mackenzie; 2007.

11. Ruthes RM, Cunha ICKO. Contribuições para o conhecimento em gerenciamento de enfermagem sobre sestão por competência. Rev Gaúcha Enferm 2007; 28(4): 570-5.

12. Dutra JS. Competências: conceitos e instrumentos para a gestão de pessoas na empresa moderna. São Paulo: Atlas; 2004.

13. Manenti AS. O processo de construção do perfil de competências gerenciais para enfermeiros coordenadores de área hospitalar [dissertação]. São Paulo: Escola de Enfermagem, Universidade de São Paulo; 2008.

14. Peres HHC, Leite MMJ, Gonçalves VLM. Educação continuada: recrutamento e seleção, treinamento e desenvolvimento, e avaliação de desempenho profissional. In: Kurcgant P, coordenadora. Gerenciamento em enfermagem. Rio de Janeiro: Guanabara Koogan; 2005. p. 138-56.

15. Souza PRM. A nova visão do Coaching na gestão por competências: integração da estratégia: como desenvolver competências na prática, diminuindo subjetividades e ajustando o foco. Rio de Janeiro: Qualitymark; 2007.

16. Ruas RL. Desenvolvimento de competências gerenciais e contribuição da aprendizagem organizacional. In: Fleury MTL, Oliveira Ir MM, organizadores. Gestão estratégica do conhecimento. São Paulo: Atlas; 2001 . p. 243-69.

17. Marx LC. Competências da enfermagem: sedimentadas no sistema primary nursing. Petrópolis: EPUB; 2006.

18. Ruthes RM, Cunha ICKO. Gestão por competências nas instituições de saúde: uma aplicação prática. São Paulo: Martinari; 2008.

19. McClelland DC. Testing for competence rather than for intelligence. Am Psycol 1973; 28(12): 1-4.

20. Le Boterf G. Desenvolvendo a competência dos profissionais. $3^{\text {a }}$ ed. Porto Alegre: Artmed; 2003.

21. Durand T. Forms of Incompetence. In: Fourth International Conference on Competence-Based Management. 1998 June 18-20, Oslo (NW). Oslo: Waikato Management School; 1998.

22. Ruas R. Gestão por competências: uma contribuição à estratégia das organizações. In: Ruas R, Antonello CS, Boff LH. Os novos horizontes da gestão: aprendizagem organizacional e competências. Porto Alegre: Bookman; 2005. p. 34-54.

23. Gaidzinski RR, Peres HHC, Fernandes MFP. Liderança: aprendizado contínuo no gerenciamento em enfermagem. Rev Bras Enferm 2004; 57(4): 464-6.

24. Vale EG, Guedes MVC. Competências e habilidades no ensino de administração em enfermagem à luz das Diretrizes Curriculares Nacionais. Rev Bras Enferm 2004; 57(4): 475-8.

25. Ramos MN. A pedagogia das competências e a psicologização das Questões sociais. São Paulo: IIEP.

26. Ministério da Educação (BR). Conselho Nacional de Educação. Câmara de Educação Superior. Resolução no 03/200 I. Institui Diretrizes Curriculares Nacionais do Curso de Graduação em Enfermagem. Diário Oficial da União 2001 nov 9; 215 :1.

27. Peres AM, Ciampone MHT. Gerência e competências gerais do enfermeiro. Texto Contexto Enferm 2006; 15(3): 492-9.

28. Conselho Regional de Enfermagem de São Paulo. Projeto competências. São Paulo: COREN; 2008.

29. Balsanelli AP, Cunha ICKO, Feldman LB, Ruthes RM, organizadoras. Competências gerenciais: desafios para o enfermeiro. São Paulo: Martinari; 2008.

30. Sherman RO, Bishop M, Eggenberger T, Karden R. Development of a leadership competency model. J Nurs Admin 2007; 37(2): $85-94$. 